\title{
Timing of cisplatin administration for chemoradiotherapy in transgenic mice bearing lens tumors
}

\author{
SHOJI KAKU ${ }^{1,2}$, NORICHIKA USHIODA ${ }^{1}$, HIROSHI ISHII ${ }^{1}$, TAKASHI MURAKAMI ${ }^{2}$, KENTARO TAKAHASHI ${ }^{2}$, \\ YUICHIRO NAKAI $^{1}$, KOICHIRO SHIMOYA ${ }^{1}$ and TAKAFUMI NAKAMURA ${ }^{1}$ \\ ${ }^{1}$ Department of Obstetrics and Gynecology, Kawasaki Medical School, Okayama; \\ ${ }^{2}$ Department of Obstetrics and Gynecology, Shiga University of Medical Science, Shiga, Japan
}

Received February 23, 2014; Accepted April 17, 2014

DOI: $10.3892 /$ or.2014.3202

\begin{abstract}
Cisplatin-based concurrent chemoradiotherapy (CCRT) has become a standard treatment for cancer of the uterine cervix. However, there have been no investigations into the optimum timing for administration of anticancerdrugs using animal models. The aim of the present study was to determine the appropriate timing for administration of the anticancer drug cisplatin in relation to delivery of radiation by assessing the antitumor activity and adverse effects of 3 different regimens in $\alpha \mathrm{T} 3$ transgenic mice bearing lens epithelial tumors. CCRT showed the strongest antitumor activity. There was a significant difference between CCRT and administration of cisplatin before radiotherapy (neoadjuvant therapy) with regard to the apoptotic effect detected by TUNEL staining, but there was no significant difference between CCRT and administration of cisplatin after radiotherapy (adjuvant therapy). Assessment of adverse effects showed that there were no significant differences in the mortality rate, weight loss, anemia and leukopenia among the 3 regimens. In conclusion, these findings obtained in an animal model suggest that cisplatin should probably not be administered before irradiation, since the antitumor effect is significantly weaker than that of CCRT or administration after irradiation, while adverse effects are similar.
\end{abstract}

\section{Introduction}

Human papillomavirus (HPV) contributes to the development of cancer of the uterine cervix. It has been reported that the E6 oncoproteins of high-risk HPV types inhibit the activity of p53 tumor suppressor protein, while the E7 oncoproteins of high-risk HPV types inhibit pRB tumor suppressor protein $(1,2)$. Cervical cancer is the second most frequent cancer among

Correspondence to: Professor Takafumi Nakamura, Department of Obstetrics and Gynecology, Kawasaki Medical School, 577 Matsushima, Kurashiki, Okayama 701-0192, Japan

E-mail: tnakamura@med.kawasaki-m.ac.jp

Key words: cisplatin, irradiation, SV40 T antigen, transgenic mice women worldwide (3) and concurrent chemoradiotherapy with cisplatin has become standard treatment for locally advanced cervical cancer (4-7). It has been confirmed that cisplatin-based concurrent chemoradiotherapy (CCRT) significantly decreases the risk of mortality due to cervical cancer by $30-50 \%(8-11)$, and also improves both disease-free survival and overall survival. However, virtually all chemotherapy agents enhance radiation damage to normal tissues, leading to severe adverse effects of concurrent chemoradiotherapy $(12,13)$.

There has been a lack of animal studies on the timing of administration of anticancer agents. Although in vitro studies using cell lines can evaluate efficacy (14-16), adverse effects cannot be properly evaluated. The aim of the present study was to determine the most appropriate timing for the administration of cisplatin with radiation through comparison of the neoadjuvant, concurrent chemoradiotherapy (CCRT) and adjuvant strategies by evaluating efficacy and adverse effects in $\alpha \mathrm{T} 3$ transgenic mice ( $\alpha \mathrm{T} 3$ mice) with undifferentiated lens epithelial tumors induced by the T antigen of SV40, which is a DNA virus resembling HPV types 16 and 18 (HPV16/18) that cause cervical cancer $(17,18)$.

\section{Materials and methods}

Animals. We produced $\alpha \mathrm{T} 3$ mice that developed crystalline lens epithelial tumors $(17,18)$. The mechanism of transformation by SV40 T antigen (TAg) of is similar to that by the E6/E7 oncoproteins of HPV16/18 since both TAg and these oncoproteins inhibit the activity of the p53 and pRB tumor suppressor proteins (19). These mice developed lens dysplasia at the embryonic stage and carcinoma in situ was observed at 8 weeks after birth. The tumors subsequently showed intraocular invasion (at 16 weeks of age), extraocular invasion (at 32 weeks of age), and metastasis to lymph nodes and other organs (after 52 weeks of age) (Fig. 1).

All procedures were performed in accordance with the Guide for the Care and Use of Laboratory Animals and were approved by the Committee on Animal Experimentation of Kawasaki Medical School. All mice had access to standard rodent chow (NMF; Oriental Yeast Co., Ltd., Japan) and water ad libitum, and were housed under pathogen-free conditions in a temperature-controlled animal room with a 12-h light/dark cycle. 

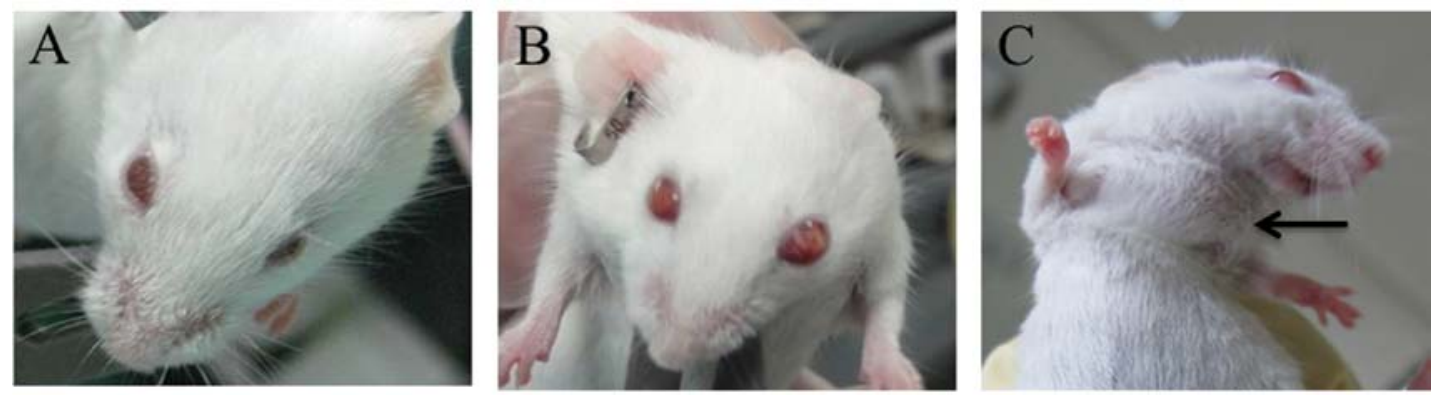

Figure 1. Lens tumors in $\alpha \mathrm{T} 3$ mice. (A) The tumor was confined inside the eyeball at 8 weeks of age. (B) The tumor showed extraocular infiltration at 16 weeks of age. (C) The tumor destroyed the eyeball and metastasized to the cervical lymph nodes (black arrow) at 52 weeks of age.

Harvesting of specimens. The mice $(\mathrm{N}=88$; body weight, $28.5 \pm 6.5 \mathrm{~g}$ ) were sacrificed at 32-36 weeks of age as extraocular invasion occurred after 32 weeks. Animals were anesthetized by intraperitoneal (i.p.) injection of sodium pentobarbital (40 mg/kg), blood was collected from the internal jugular vein and the mice were euthanized. Then the eyeballs were carefully resected, fixed in $4 \%$ formalin, embedded in paraffin and cut into $4 \mu \mathrm{m}$ sections. These sections were deparaffinized and stained with hematoxylin and eosin $(\mathrm{H} \& \mathrm{E})$ staining or were processed for terminal deoxynucleotidyl transferase dUTP nick end-labeling (TUNEL) staining.

Chemotherapy. Cisplatin (Nippon Kayaku, Tokyo, Japan) was reconstituted with sterile $0.9 \%$ saline in a laminar air-flow hood under sterile conditions. Our preliminary experiment showed that the $50 \%$ lethal dose $\left(\mathrm{LD}_{50}\right)$ of cisplatin was $16 \mathrm{mg} / \mathrm{kg}$, therefore animals received i.p. chemotherapy with cisplatin at a dose of $2 \mathrm{mg} / \mathrm{kg}\left(1 / 8\right.$ of the $\left.\mathrm{LD}_{50}\right)$. This dose was approximately equivalent to the clinical dose used for treatment of cervical cancer in humans $\left(40 \mathrm{mg} / \mathrm{m}^{2}\right)(20)$ based on the ratio of mass and body surface area between mice and adult human females (21).

Irradiation. Whole-body irradiation was performed using an MBR-1520R3 X-Ray generator (Hitachi Medical Co., Tokyo, Japan) and the mice received daily fractions of $2.0 \mathrm{~Gy}$ from day 0 to 4 (total, $10.0 \mathrm{~Gy}$ ). The radiation dose and schedule were selected to be similar to those used to treat cervical cancer in humans. (In our preliminary experiment, mice received 5.0-10.0 Gy of whole-body irradiation as a single dose and animals administered 10.0 Gy died within two weeks.)

Treatment plan. To determine the optimum timing for administration of cisplatin and irradiation, we divided the mice into an irradiation-first group (adjuvant group), a concurrent chemoradiotherapy group (CCRT group) and a cisplatin-first group (neoadjuvant group). Three control groups were also studied, and they received no treatment, cisplatin alone and irradiation alone. Specimens were obtained at three weeks after administration of cisplatin or after starting irradiation (three weeks after starting the second treatment in the neoadjuvant and adjuvant groups).

The mice were divided into the following six groups. Group $1(\mathrm{~N}=11)$ was the untreated control group, Group 2 $(\mathrm{N}=17)$ was the cisplatin control group that received i.p. cisplatin on day 0 , and Group $3(\mathrm{~N}=18)$ was the irradiation control group that received $2 \mathrm{~Gy} /$ day from day 0 to 4 . Group 4 $(\mathrm{N}=14)$ was the CCRT group, which received i.p. cisplatin on day 0 and radiation at 2 Gy/day on days $0-4$. Group $5(\mathrm{~N}=13)$ was designated as the irradiation-first group, and received radiation at 2 Gy/day on days 0-4 and was administered i.p. cisplatin on day 7. Group $6(\mathrm{~N}=15)$ was designated as the cisplatin-first group, and received i.p. cisplatin on day 0 and radiation at $2 \mathrm{~Gy} /$ day on days 7 to 11 . In all groups, specimens were harvested on day 20. Before treatment (on day 0) and after treatment (on the day of harvesting), the body weight and eyeball size in all mice were measured.

To investigate the antitumor activity of each treatment, we determined the reduction rate of eyeball diameter and assessed apoptosis of tumor cells by TUNEL staining. To investigate adverse effects, we assessed the mortality rate, the changes of body weight, and the hemoglobin and leukocyte count. The hemoglobin was measured in venous blood obtained at the time of sacrifice using an ABL800 (Radiometer Medical, Tokyo, Japan), while leukocytes were counted by S.K., N.U. and H.I. using an erythrocytometer and the average of their results was calculated.

Detection of apoptosis. Apoptosis of tumor cells was detected by the TUNEL method using an ApopTag Plus Peroxidase In situ Apoptosis Detection kit (Chemicon International, Temecula, CA, USA). Briefly, after deparaffinization and rehydration, samples were pretreated by incubation with proteinase $\mathrm{K}$ ( $2 \mu \mathrm{g} / \mathrm{ml}$; Merck, Darmstadt, Germany) for $15 \mathrm{~min}$ at $37^{\circ} \mathrm{C}$. After endogenous peroxidase was inactivated by incubation with $3 \% \mathrm{H}_{2} \mathrm{O}_{2}$ in phosphate-buffered saline (PBS) for $5 \mathrm{~min}$, sections were rinsed with PBS and then incubated with terminal deoxynucleotidyl transferase (TdT) buffer containing $1 \mathrm{mM}$ of cobalt- $\mathrm{HCl}, 0.5 \mathrm{U} / 1$ terminal transferase and $0.4 \mu \mathrm{M}$ of digoxigenin-11-deoxyuridine triphosphate (dUTP) in a humidified chamber for $60 \mathrm{~min}$ at $37^{\circ} \mathrm{C}$. The reaction was stopped by adding TdT stop buffer, anti-digoxigenin peroxidase conjugate was added, and incubation was carried out for $30 \mathrm{~min}$. As a negative control, slides were incubated without TdT. After visualization of the reaction products with diaminobenzidine (Sigma Chemical Co., St. Louis, MO, USA), nuclei were counterstained with methyl green. Since many tumors showed central necrosis (Fig. 5A-a), even in the control group, we counted the number of apoptotic cells (TUNELpositive cells) outside the central necrotic area. 


\begin{tabular}{|c|c|c|}
\hline & $\begin{array}{c}\text { Number of deaths } \\
\text { (Mortality rate) }\end{array}$ & \\
\hline Group 1 (untreated group: $\mathrm{N}=11$ ) & $1(9.1 \%)$ & \\
\hline Group 2 ( cisplatin group: $N=17$ ) & $3(17.6 \%)$ & $N$ \\
\hline Group 3 (irradiation group: $\mathrm{N}=18$ ) & $1(5.6 \%)$ & \\
\hline Group 4 (CCRT group: $\mathrm{N}=14$ ) & $3(21.4 \%)$ & NSC \\
\hline Group 5 (irradiation-first group: $\mathrm{N}=13$ ) & $2(15.4 \%)$ & NS \\
\hline Group 6 (cisplatin-first group: $\mathrm{N}=15$ ) & $4(26.7 \%)$ & \\
\hline
\end{tabular}

Figure 2. Comparison of the mortality rate between each group. The mortality rate was the highest in Group 6, but there was no significant difference from any of the other groups. NS, not significant.

Statistical analysis. Data were analyzed by the Chi-square test and the Mann-Whitney U test using StatFlex version 6.0 software (Artech Co., Ltd., Osaka, Japan). P $<0.05$ was considered to indicate statistically significant differences.

\section{Results}

The number of mice that died before the scheduled day for harvesting specimens was 1/11 (9.1\%) in Group 1, 3/17 (17.6\%) in Group 2, 1/18 (5.6\%) in Group 3, 3/14 (21.4\%) in Group 4 , $2 / 13(15.4 \%)$ in Group 5 and $4 / 15(26.7 \%)$ in Group 6 . The mortality rate was the highest in Group 6 , but there was no significant difference from the rate in Group $1(\mathrm{P}=0.261$; Fig. 2). Mice that died early were excluded from the analysis of the antitumor activity and adverse effects, except mortality. Thus, the number of animals analyzed in each group was 10 in Group 1, 14 in Group 2, 17 in Group 3, 11 in Group 4, 11 in Group 5 and 11 in Group 6.

In each group, antitumor activity was assessed by comparison of the tumor diameter reduction rate between before and after treatment (Fig. 3). In Group 4, the tumors showed the most marked decrease in size and there was a significant difference between Group 4 and $2(\mathrm{P}=0.019)$, although there was no significant difference between Group 4 and Groups 3, 5 or 6 . Representative images obtained from Groups 2 and 4 before and after therapy are shown in Fig. 4. We also evaluated apoptosis in each group to examine the effect of treatment. Apoptotic cells were defined as TUNEL-positive cells with obvious nuclear immunoreactivity (Fig. 5A and B). Immunohistochemical analysis revealed that the median number of TUNEL-positive cells in lens tissue per 10 highpower fields was 15.5 (range, 4-37) in Group 1, 15.5 (range, 5-42) in Group 2, 18 (range, 4-41) in Group 3, 32 (range, 11-49) in Group 4, 24.5 (range, 8-47) in Group 5 and 23 (range, 8-40) in Group 6. The number of TUNEL-positive cells was the highest in Group 4, and there was a significant difference between the number in Group 4 and that in Groups 2, 3 or 6 ( $\mathrm{P}<0.01, \mathrm{P}<0.01$ and $\mathrm{P}=0.031$, respectively) (Fig. 6).

Finally, we compared the adverse effects of each regimen. Investigation of the changes of body weight showed that there were no significant differences between Group 1 and any other group (Fig. 7). Therefore, the anorectic effect of treatment did not show marked differences among the groups. In addition,

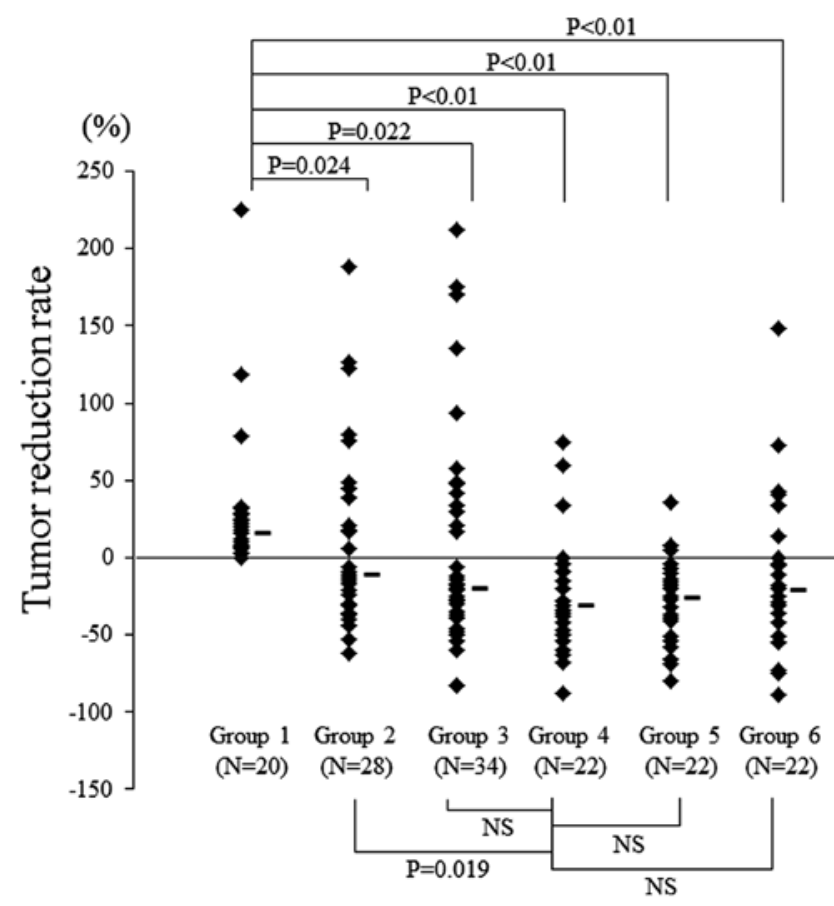

Figure 3. Tumor reduction rate. In Group 4, tumors showed the greatest reduction in size. There was a significant difference between Group 4 and Group $2(\mathrm{P}=0.019)$, but not between Group 4 and Groups 3, 5 or 6 . NS, not significant.

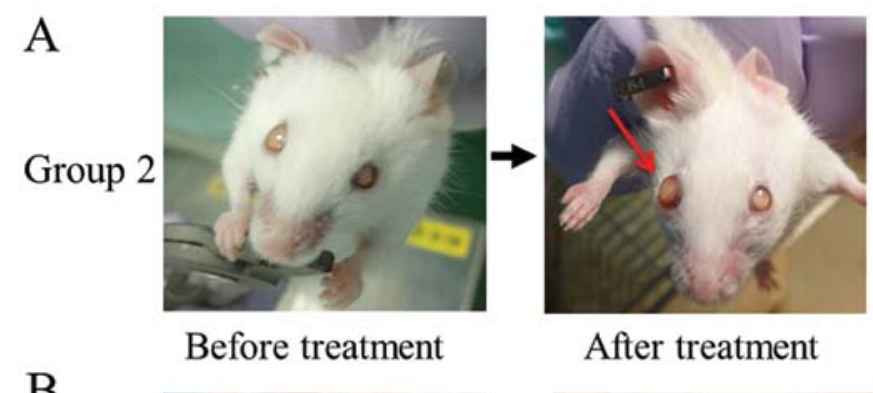

B

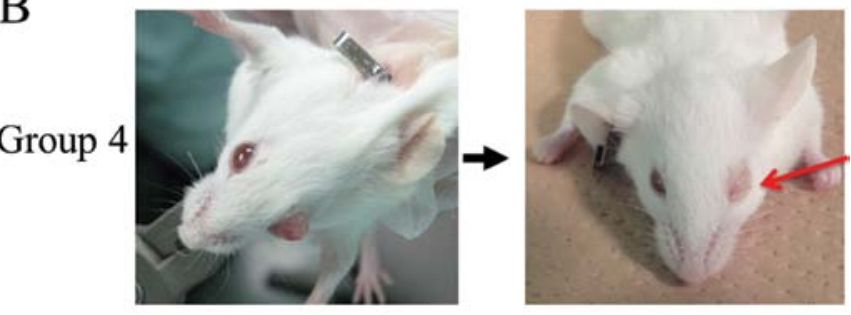

Figure 4. Representative images of mice from Groups 2 and 4 before and after treatment. (A) A mouse from Group 2. The eyeball is larger after treatment than before treatment. (B) A mouse from Group 4. The eyeball showed a marked decrease in size after treatment.

we examined the severity of myelosuppression by measuring the hemoglobin and leukocyte count after treatment. We found that the hemoglobin did not show a significant difference between Group 1 and any of the other groups (Fig. 8A). The leukocyte count was the lowest in Group 4 and there was a significant difference compared with Group $2(\mathrm{P}=0.004)$, but there was no significant difference between Group 4 and Groups 3, 5 or 6 (Fig. 8B). 
A
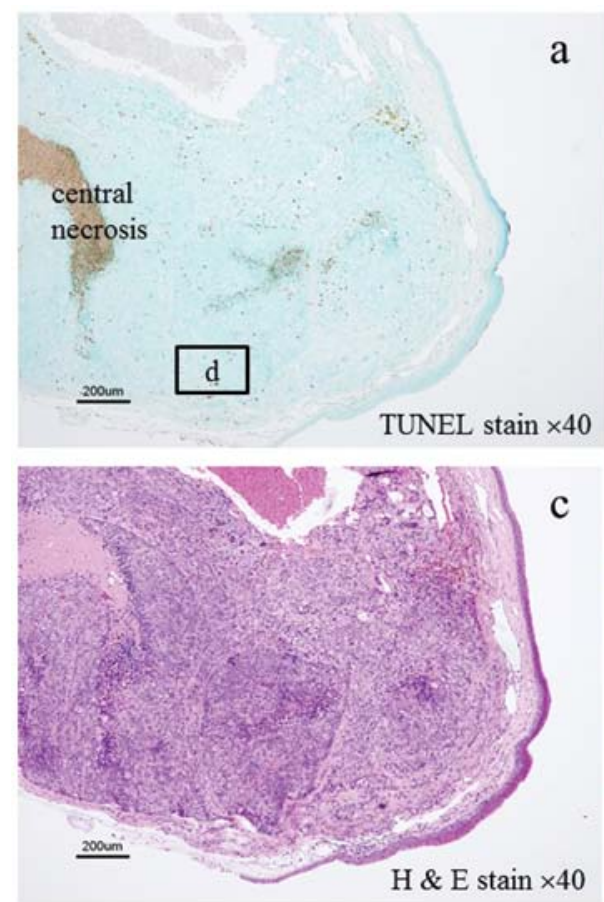

a
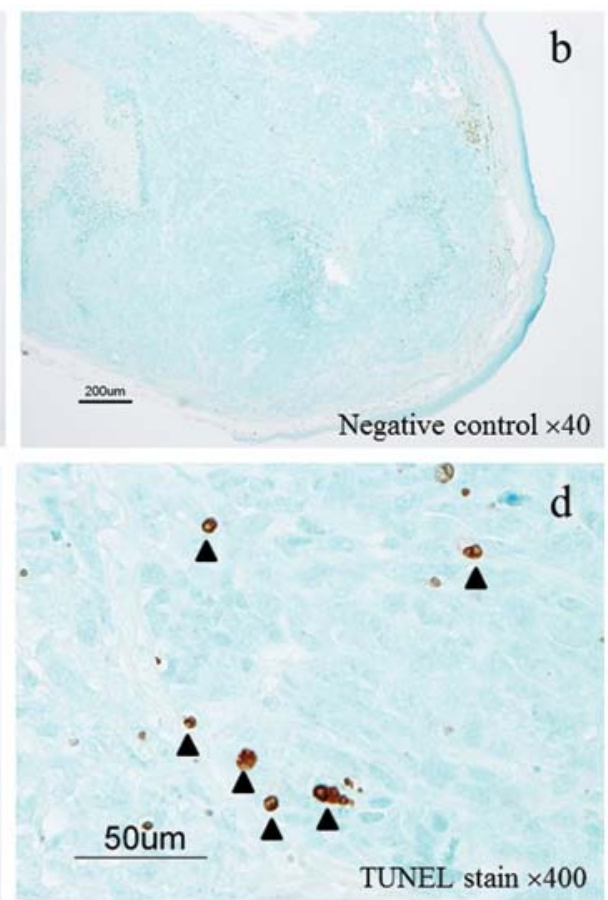

B

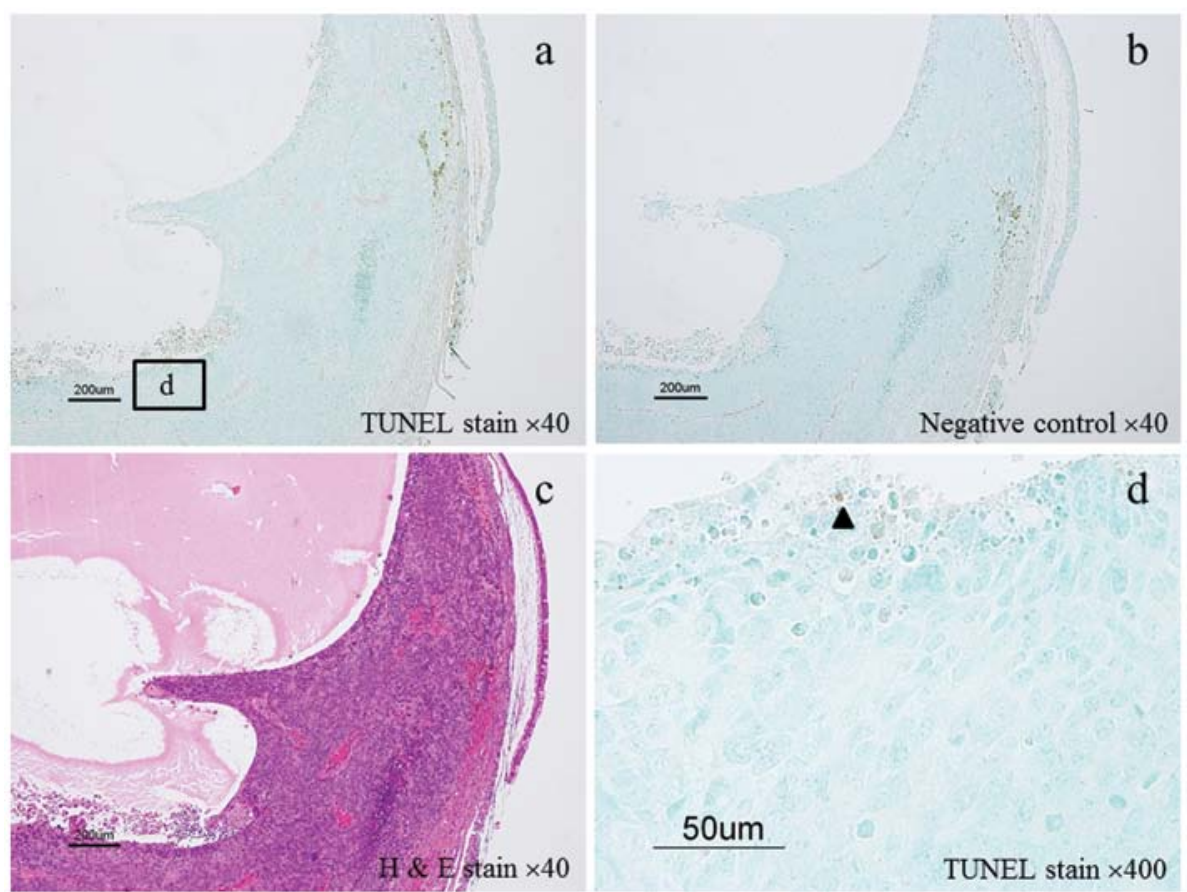

Figure 5. Detection of TUNEL-positive cells in lens tissue. (A) Eyeball of a mouse from Group 4 with numerous TUNEL-positive cells in the lens tissue. (B) Eyeball of a mouse from Group 2 with few TUNEL-positive cells in the lens tissue. a, TUNEL staining, magnification, x40; b, negative control, magnification, $\mathrm{x} 40 ; \mathrm{c}, \mathrm{H} \& \mathrm{E}$ staining, magnification, $\mathrm{x} 40$ and $\mathrm{d}$, TUNEL staining, magnification, $\mathrm{x} 400$.

\section{Discussion}

To improve the outcome of treatment for locally advanced cervical cancer, radiotherapy has become mainstream and, to increase the effect of radiation chemotherapy, agents are administered before radiotherapy, concurrently with radiotherapy or after radiotherapy. However, only concurrent chemoradiation has been proven to improve disease-free survival and overall survival in patients with cervical cancer (8-11), while there have been a number of reports that performing chemotherapy before radiotherapy does not improve survival (22-26). The anticancer drug that has proved to be most effective with radiation is cisplatin either alone or in combination with other agents such as 5-fluorouracil (4-7). Therefore, CCRT with cisplatin has become the standard treatment for locally advanced cervical cancer.

The effect of irradiation is presumably enhanced by performing concurrent chemotherapy due to a radiosensitizing effect of anticancer drugs that enhances initial radiation damage to DNA. For example, cisplatin interacts with nucleophilic sites 


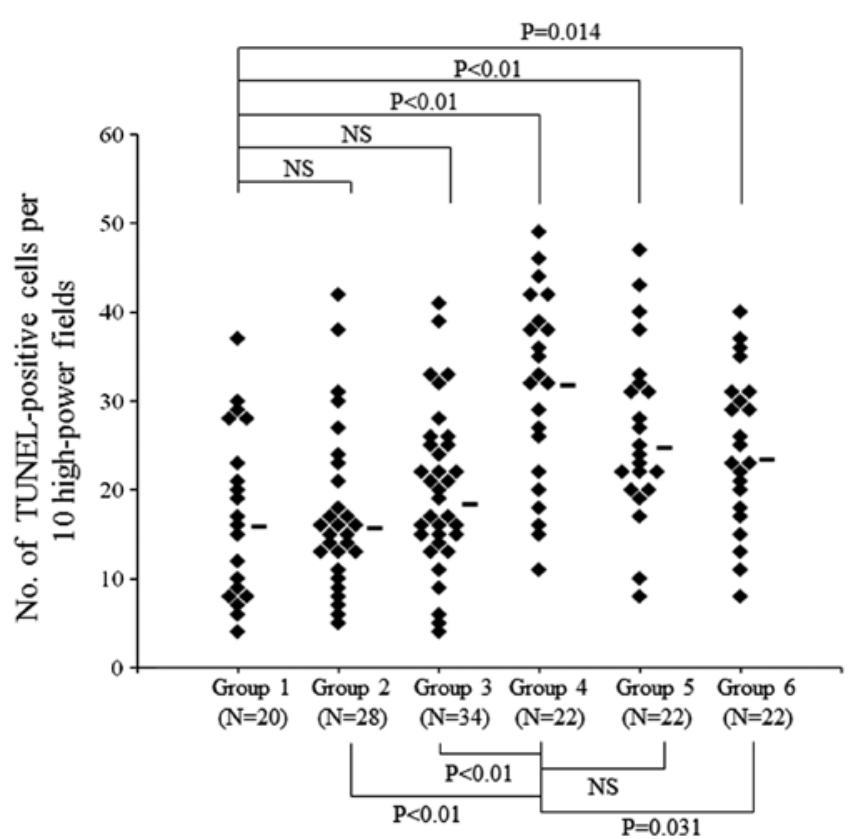

Figure 6. The number of TUNEL-positive cells per 10 high-power fields in lens tissue. The number of TUNEL-positive cells was the highest in Group 4 , and there was a significant difference between Group 4 and Groups 2, 3 or 6 $(\mathrm{P}<0.01, \mathrm{P}<0.01$ and $\mathrm{P}=0.031$, respectively). NS, not significant.

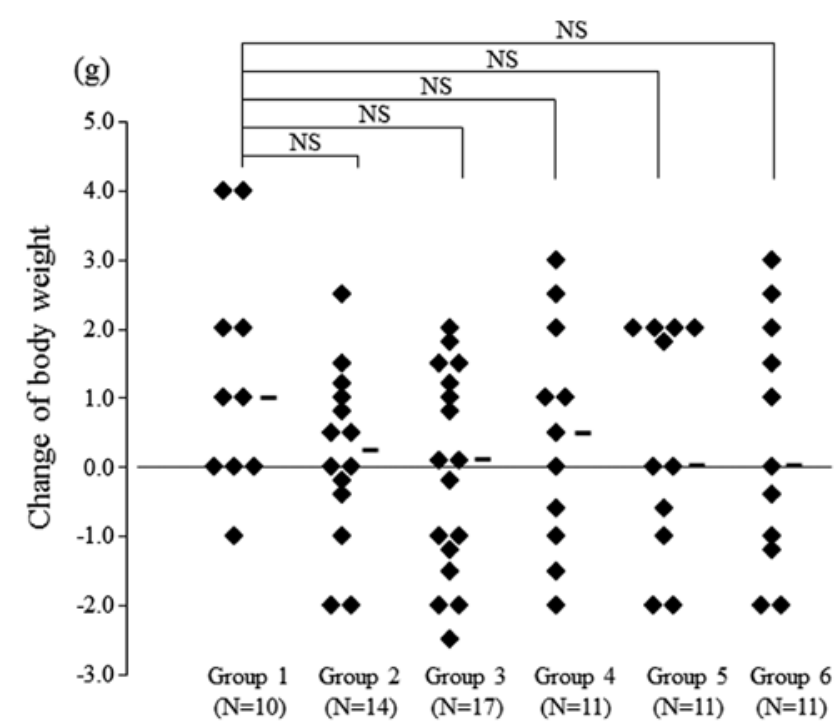

Figure 7. Changes of body weight. Comparison of the changes of body weight showed that there was no significant difference between Group 1 and any of the other groups. NS, not significant.

on DNA or RNA to form intra-and inter-strand crosslinks (12). Second, chemotherapy agents inhibit cellular repair processes and exacerbate radiation damage. Grégoire et al reported that the effect of fludarabine on radiocurability in mice was greater when it was combined with fractionated radiation than when it was combined with a single dose of radiation (27). Third, chemotherapy can cause the accumulation of cells in the radiosensitive phases of the cell cycle (the $\mathrm{G} 2$ and $\mathrm{M}$ phases) or eliminate cells in the radioresistant phase (S-phase) (28-30). Some in vitro studies using human cervical squamous cell carcinoma cell lines have already investigated the timing of
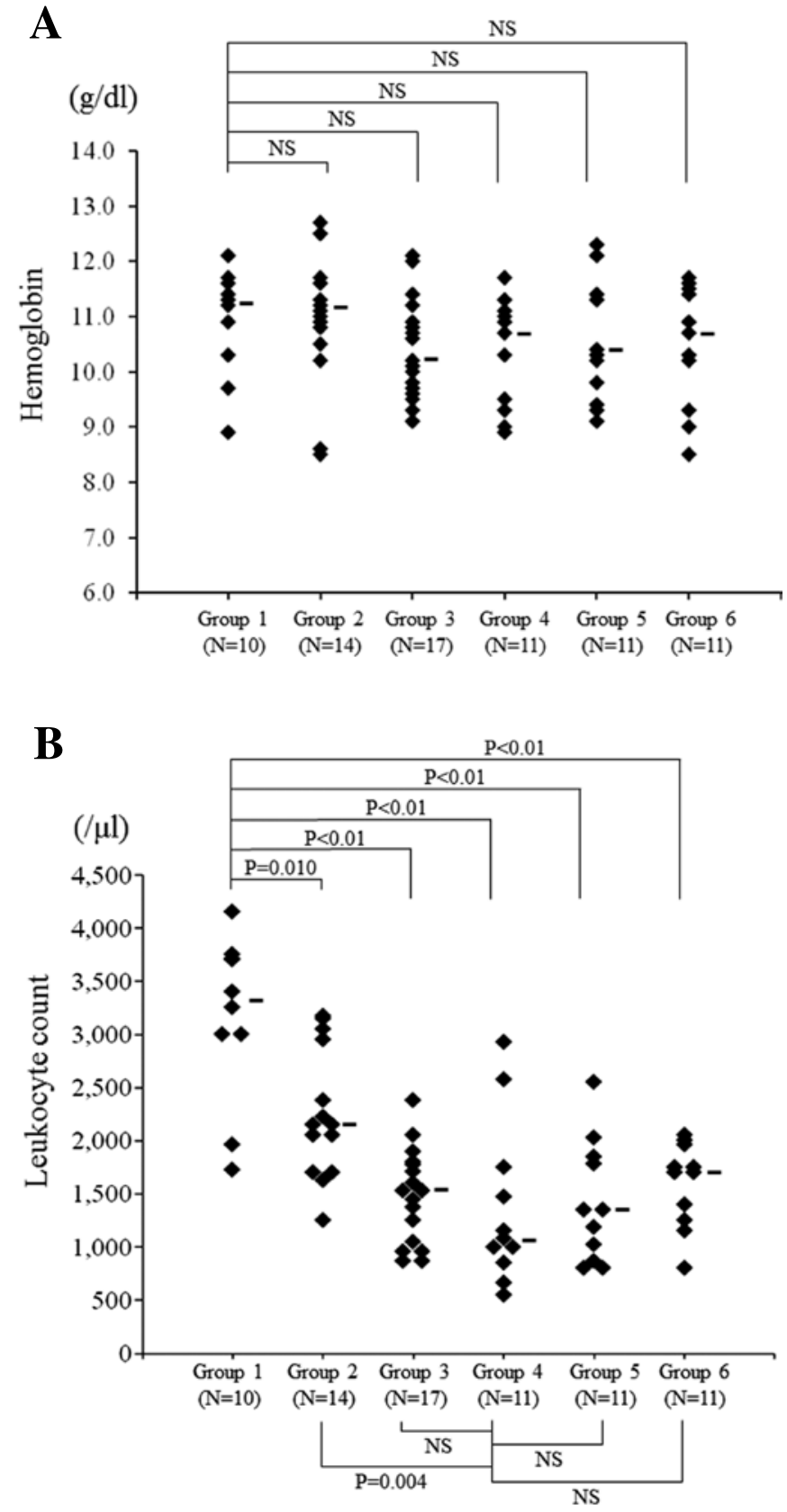

Figure 8. Hemoglobin and leukocyte count. (A) Comparison of the hemoglobin. There was no significant difference of hemoglobin between Group 1 and any of the other groups. (B) Comparison of the leukocyte count. Group 4 had the lowest leukocyte count and there was a significant difference compared with Group 2 ( $\mathrm{P}=0.004)$, but there was no significant difference between Group 4 and Groups 3, 5 or 6. NS, not significant.

anticancer drug administration $(15,16)$. Tanaka et al reported that sensitivity to nedaplatin was enhanced by irradiation and this effect was significantly greater when cells were treated $8 \mathrm{~h}$ before or $8 \mathrm{~h}$ after irradiation than when they were treated concurrently with irradiation (16). They also reported that 5 of the 6 etoposide-resistant subclones established from ME180 cells showed significant radioresistance, indicating that etoposide should be administered to patients with advanced cervical squamous cancer after the completion of radiotherapy (15).

Although it is inevitable that CCRT will be associated with enhanced acute toxicity $(12,13)$, there has been a lack of 
animal studies on the relation between adverse effects and the timing of administration of anticancer drugs. Therefore, we performed the present investigation using $\alpha \mathrm{T} 3$ transgenic mice bearing SV40-induced undifferentiated lens epithelial tumors $(17,18)$. Comparison of the three combined treatment groups showed that the antitumor activity of CCRT was superior with respect to the tumor reduction rate and the apoptotic effect, although leukopenia was also most severe. In contrast, when cisplatin was administered before radiotherapy the antitumor activity (both tumor reduction rate and the apoptotic effect) was lower than with CCRT or with administration of cisplatin after radiotherapy, and there was a significant difference in the extent of apoptosis between the CCRT group and the cisplatin-first group $(\mathrm{P}=0.031)$. Although leukopenia was less severe in the cisplatin-first group, there was no significant difference from the other groups. These results suggest that it may be unwise to administer cisplatin before radiotherapy. It was recently reported that neoadjuvant chemotherapy with weekly paclitaxel and carboplatin before CCRT is beneficial for locally advanced cervical carcinoma $(31,32)$. Therefore, further studies are needed to examine the effectiveness of such agents with radiotherapy in our animal model.

In conclusion, the present study performed on mice did not show the superiority of CCRT over administration of chemotherapy after radiotherapy with respect to efficacy and adverse effects, therefore we could not demonstrate that CCRT is the optimum treatment. However, our findings in this animal model demonstrated that chemotherapy with cisplatin should probably not be performed before irradiation for the treatment of cancer.

\section{Acknowledgements}

We thank Miss Yoshimi Harada for handling of the mice and Mr. Nobuhisa Iwachidou for the technical assistance with immunostaining. This study was supported by multiple Research Project Grants (nos. 20-111N, 21-122, 22-A68, 24Base-27 and 25Base-99) from Kawasaki Medical School.

\section{References}

1. Kessis TD, Slebos RJ,Nelson WG, et al: Human papillomavirus 16 E6 expression disrupts the p53-mediated cellular response to DNA damage. Proc Natl Acad Sci USA 90: 3988-3992, 1993.

2. Nees M, Geoghegan JM, Munson P, et al: Human papillomavirus type 16 E6 and E7 proteins inhibit differentiation-dependent expression of transforming growth factor- $\beta 2$ in cervical keratinocytes. Cancer Res 60: 4289-4298, 2000.

3. Parkin DM, Pisani P and Ferlay J: Estimates of the worldwide incidence of eighteen major cancers in 1985. Int J Cancer 54: 594-606, 1993

4. Runowicz CD, Wadler S, Rodriguez-Rodriguez L, et al: Concomitant cisplatin and radiotherapy in locally advanced cervical carcinoma. Gynecol Oncol 34: 395-401, 1989.

5. Alberts DS, Garcia D and Mason-Liddil N: Cisplatin in advanced cancer of the cervix: an update. Semin Oncol 18: 11-24, 1991

6. Malfetano J, Keys H, Kredentser D, Cunningham M, Kotlove D and Weiss L: Weekly cisplatin and radical radiation therapy for advanced, recurrent, and poor prognosis cervical carcinoma. Cancer 71: 3703-3706, 1993.

7. Whitney CW, Sause W, Bundy BN, et al: Randomized comparison of fluorouracil plus cisplatin versus hydroxyurea as an adjunct to radiation therapy in stage IIB-IVA carcinoma of the cervix with negative para-aortic lymph nodes: a Gynecologic Oncology Group and Southwest Oncology Group study. J Clin Oncol 17: $1339-1348,1999$.
8. Sorbe B, Bohr L, Karlsson L and Bermark B: Combined external and intracavitary irradiation in treatment of advanced cervical carcinomas: Predictive factors for local tumor control and early recurrences. Int J Oncol 36: 371-378, 2010.

9. Morris M, Eifel PJ, Lu J, et al: Pelvic radiation with concurrent chemotherapy compared with pelvic and para-aortic radiation for high-risk cervical cancer. N Engl J Med 340: 1137-1143, 1999.

10. Rose PG, Bundy BN, Watkins EB, et al: Concurrent cisplatinbased radiotherapy and chemotherapy for locally advanced cervical cancer. N Engl J Med 340: 1144-1153, 1999.

11. Eifel PJ, Winter K, Morris M, et al: Pelvic irradiation with concurrent chemotherapy versus pelvic and para-aortic irradiation for high-risk cervical cancer: an update of radiation therapy oncology group trial (RTOG) 90-01. J Clin Oncol 22: 872-880, 2004.

12. Vokes EE and Weichselbaum RR: Concomitant chemoradiotherapy: rationale and clinical experience in patients with solid tumors. J Clin Oncol 8: 911-934, 1990.

13. Tannock IF: Treatment of cancer with radiation and drugs. J Clin Oncol 14: 3156-3174, 1996.

14. Randall LM, Monk BJ, Moon J, et al: Prospective evaluation of an in vitro radiation resistance assay in locally advanced cancer of the uterine cervix: a Southwest Oncology Group Study. Gynecol Oncol 119: 417-421, 2010.

15. Tanaka T, Bai T, Yukawa K and Umesaki N: Optimal combination chemotherapy and chemoradiotherapy with etoposide for advanced cervical squamous cancer cells in vitro. Oncol Rep 15: 939-947, 2006.

16. Tanaka T, Yukawa K and Umesaki N: Radiation reduces carboplatin sensitivity and enhances nedaplatin sensitivity in cervical squamous cell carcinoma in vitro. Eur J Gynaecol Oncol 28: 352-355, 2007.

17. Egwuagu CE, Li W, Yu CR, et al: Interferon- $\gamma$ induces regression of epithelial cell carcinoma: critical roles of IRF-1 and ICSBP transcription factors. Oncogene 25: 3670-3679, 2006.

18. Zheng HC, Nakamura T, Zheng Y, et al: SV40 T antigen disrupted the cell metabolism and the balance between proliferation and apoptosis in lens tumors of transgenic mice. J Cancer Res Clin Oncol 135: 1521-1532, 2009.

19. Fujii M, Ide A, Nakabayashi K, Joguchi A, Ogino H and Ayusawa D: The introduction of dominant-negative p53 mutants suppresses temperature shift-induced senescence in immortal human fibroblasts expressing a thermolabile SV40 large T antigen. J Biochem 125: 531-536, 1999.

20. Dueñas-González A, Cetina-Perez L, Lopez-Graniel C, et al: Pathologic response and toxicity assessment of chemoradiotherapy with cisplatin versus cisplatin plus gemcitabine in cervical cancer: a randomized Phase II study. Int J Radiat Oncol Biol Phys 61: 817-823, 2005.

21. Verbraecken J, Van de Heyning P, De Backer W and Van Gaal L: Body surface area in normal-weight, overweight, and obese adults. A comparison study. Metabolism 55: 515-524, 2006.

22. Kumar L, Kaushal R, Nandy M, et al: Chemotherapy followed by radiotherapy versus radiotherapy alone in locally advanced cervical cancer: a randomized study. Gynecol Oncol 54: 307-315, 1994.

23. Tattersall MH, Lorvidhaya V, Vootiprux V, et al: Randomized trial of epirubicin and cisplatin chemotherapy followed by pelvic radiation in locally advanced cervical cancer. Cervical Cancer Study Group of the Asian Oceanian Clinical Oncology Association. J Clin Oncol 13: 444-451, 1995.

24. Sundfør K, Tropé CG, Högberg T, et al: Radiotherapy and neoadjuvant chemotherapy for cervical carcinoma. A randomized multicenter study of sequential cisplatin and 5-fluorouracil and radiotherapy in advanced cervical carcinoma stage $3 \mathrm{~B}$ and $4 \mathrm{~A}$. Cancer 77: 2371-2378, 1996.

25. Shueng PW, Hsu WL, Jen YM, Wu CJ and Liu HS: Neoadjuvant chemotherapy followed by radiotherapy should not be a standard approach for locally advanced cervical cancer. Int J Radiat Oncol Biol Phys 40: 889-896, 1998.

26. Neoadjuvant Chemotherapy for Locally Advanced Cervical Cancer Meta-analysis Collaboration: Neoadjuvant chemotherapy for locally advanced cervical cancer: a systematic review and meta-analysis of individual patient data from 21 randomised trials. Eur J Cancer 39: 2470-2486, 2003.

27. Grégoire V, Hunter NR, Brock WA, Hittelman WN, Plunkett W and Milas L: Improvement in the therapeutic ratio of radiotherapy for a murine sarcoma by indomethacin plus fludarabine. Radiat Res 146: 548-553, 1996. 
28. Milas L, Hunter N, Mason KA, Milross C and Peters LJ: Tumor reoxygenation as a mechanism of taxol-induced enhancement of tumor radioresponse. Acta Oncol 34: 409-412, 1995.

29. Milross CG, Mason KA, Hunter NR, et al: Enhanced radioresponse of paclitaxel-sensitive and -resistant tumours in vivo. Eur J Cancer 33: 1299-1308, 1997.

30. Suzuki M, Nakamatsu K, Kanamori S, Masunaga S and Nishimura Y: Additive effects of radiation and docetaxel on murine SCCVII tumors in vivo: special reference to changes in the cell cycle. Radiat Res 159: 799-804, 2003.
31. Singh RB, Chander S, Mohanti BK, et al: Neoadjuvant chemotherapy with weekly paclitaxel and carboplatin followed by chemoradiation in locally advanced cervical carcinoma: a pilot study. Gynecol Oncol 129: 124-128, 2013.

32. McCormack M, Kadalayil L, Hackshaw A, et al: A phase II study of weekly neoadjuvant chemotherapy followed by radical chemoradiation for locally advanced cervical cancer. Br J Cancer 108: 2464-2469, 2013. 